\title{
Polytechnic Admissions in Karnataka at Crossroads
}

\author{
Siddharama Adi \\ Lecturer, \\ Department of Mechanical Engineering, \\ Motichand Lengade Bharatesh Polytechnic, Belagavi, Karnataka, India.
}

\begin{abstract}
The Polytechnic education system in Karnataka has come a long way over the last few decades providing the middle level technical personnel which has contributed significantly towards the development of manufacturing, construction and service sectors. The investment in the Polytechnic education is a necessary input for national industrial development. The purpose of Polytechnic education which is an important component of technical education, is to train middle level technical manpower. These middle level technical persons are very crucial as they act as a liaison between their colleagues at senior and junior levels. The broad objective of this paper is to examine the trend in the growth of Diploma/Polytechnic colleges, the intake capacity and also the enrollment of students to the Polytechnic colleges in Karnataka. Over the period of time there is an expansion in the number of Polytechnic colleges in the state to meet the enhanced demands of the industries whereas on the contrary, the number of students enrolling to these colleges is showing a declining trend. Hence the need of the hour is to consolidate and strengthen the ongoing Polytechnic programmes incorporating the latest developments in the technical field. The policy interventions suggested in this paper may help to reverse this trend.
\end{abstract}

Keywords-Polytechnic education, technical personnel, intake capacity, and enrollment.

\section{INTRODUCTION}

In India, technical education is recognized as the most significant component of human resource development, since it has great potential for adding value to products and services, for contributing to the national economy and for improving the quality of life of the people. Over the last six decades there is a phenomenal growth of technical education in India. Technical education in India has been operating at different levels viz., Certificate, Diploma, Under Graduate, Post Graduate and Research in different engineering disciplines. The government of India and the state governments have been making consistent efforts for qualitative improvement and quantitative expansion of the technical education system particularly the Polytechnic education system, in consistent with the rapid changes taking place in the industrial and technology scenario of India. In the rapidly changing world of technology, India needs to adapt itself to these changes. In this context, the Polytechnic education system is a major contributor in the process of restructuring Indian industrial and manufacturing sectors as it provides the middle order technical manpower to facilitate significantly for the establishment of an impressive infrastructure in the industrial, construction and service sectors. In view of these developments, the broad objective of this paper is to examine the trend in the growth of
Diploma/Polytechnic colleges, the intake capacity and also the enrollment of students to the Polytechnic colleges in Karnataka.

\section{PRESENT SCENARIO}

Since independence, the Government of India and the state Governments have been making continuous efforts for improvement both in quality and quantity in the Polytechnic education system. In order to ensure the standard of technical education, a statuary authority - The All India Council for Technical Education (AICTE) was set up in 1945 [4]. Till today AICTE is responsible for planning, formulation and maintenance of norms and standards, quality assurance through Accreditation, funding in priority areas, monitoring and evaluation, maintaining parity of certification and awards and facilitating coordinated and integrated development along with monitoring of technical education in the country. At present, the Polytechnics in the country offer three year generalized diploma courses in various branches of engineering and non engineering courses. The entry qualification for diploma programmes in most of the states is $10^{\text {th }} /$ SSLC pass. One of the noteworthy achievements of Karnataka during the post independence period is the remarkable growth of technical education particularly, the Polytechnic education. The Department of Technical Education (DTE), Government of Karnataka, is the regulating authority for the Polytechnic education in Karnataka. In Karnataka, the Polytechnic education is a three tired system consisting of Government, Government Aided and self financing Institutions [2]. Through the DTE, the Government finances the Government Polytechnics. The Government Aided institutions manage their finances partially from the Government and partially from their own resources. Self financing Institutions generate their funds on their own but are governed by the rules and regulations of the DTE. The admission process is conducted for both Government and aided Polytechnic colleges in the state, through the District Nodal Centers. Since 2011-12, first time On-line Interactive Diploma admissions are being conducted for the students applying for $1^{\text {st }}$ year Polytechnic course [1]. Students are informed about the information regarding the online admission process on a separate website. Further, the merit number, counseling dates, etc. are provided to the students in advance through the sms. The majority of the students seeking admission to the diploma courses hail from generally poor socio-economic backgrounds, both from rural and urban areas. 
In India, the number of Polytechnics has increased considerably from 1,203 in 2001-02 to more than 2,128 colleges in the year 2019-20 with corresponding rise in intake. There is comparatively higher proportion of Polytechnic colleges in southern states (46\%) [3]. The number of Polytechnic colleges in Karnataka has increased very rapidly over the last few decades. The periodical growth of Polytechnic colleges in Karnataka is presented in table 1. It is evident from this table that, in Karnataka, at the time of independence there were only two Polytechnic colleges whereas in 1980 the same increased to 26 over a period of 33 years. Later slowly the number of colleges increased, especially after the year 2000, there was more vibrant growth of these colleges. The maximum number of colleges i.e. 299 was in the year 2017-18 but the very next year i.e. in the year 2018-19, the number of colleges declined to 278 as 21 colleges were closed [1]. At present in 2019-20, as per the data provided by the AICTE a total of 300 Polytechnic colleges are functioning in Karnataka including Government Tool Room and Training centers [7].

Table 1 : Periodical Growth of Polytechnic Colleges in Karnataka

\begin{tabular}{|c|c|}
\hline Year & Polytechnic Colleges \\
\hline Before 1947 & 2 \\
\hline $1947-80$ & 26 \\
\hline $1980-81$ & 35 \\
\hline $1990-91$ & 136 \\
\hline $2000-01$ & 169 \\
\hline $2010-11$ & 283 \\
\hline $2017-18$ & 299 \\
\hline $2018-19$ & $278(-21)$ \\
\hline Total & $\mathbf{2 7 8}$ \\
\hline \multicolumn{2}{|c|}{ Source: Compiled from Annual Administrative }
\end{tabular}

Reports 2008-09 and 2018-19

A comparative statistics of district wise distribution of Polytechnic colleges in Karnataka between the years 2004 and 2019 is provided in the table 2. In this table, it may be noted that between the years 2004 and 2019, the total number of Polytechnic colleges increased from 179 to 278 exhibiting an increment of $35.6 \%$. In the year 2004, out of the total 179 colleges, nearly $21 \%$ were government colleges and $79 \%$ private colleges, whereas in the year 2019 nearly $30 \%$ of the Polytechnic colleges were under the government management and $70 \%$ were under private management. This is due to the fact that, the government has started several Polytechnic colleges in the rural areas of Karnataka during the last decade. Among the 30 districts of Karnataka, in both the years 2004 and 2019, Bangalore Urban District is having the maximum number of colleges i.e. 54 and 58 followed by Belagavi District with 10 and 15 respectively [1]. At the other end, Chamarajnagar and Kodagu Districts are having 1 and 2 colleges respectively in both the years 2004 and 2019 indicating no increase in the number. The rest of the Districts are having less than 15 Polytechnic colleges.

As the number of Polytechnic colleges increased over a period of time accordingly, the intake capacity also has expanded. The table 3 displays the statistics regarding the category of Polytechnic colleges, their intake capacity and admission details for a period of last 10 years between 200910 and 2018-19. During this period only five Polytechnic colleges were added to the existing number of 273 making the total number 278 with the percentage increase of 1.8 points. In all these colleges, in the year 2009-10, the intake capacity of students was 73,782 , the same increased to 86,894 students in the year 2018-19. This leads to the overall increase in the intake capacity to the extent of $15 \%$ during this period. But the admission statistics reveals the other side of the situation. In the year 2009-10, 55,824 students i.e. $75.6 \%$ of total intake capacity, had taken admission for the various courses in the Polytechnic colleges. But in the year 2018-19, only 48,394 students i.e. $55.7 \%$ of total intake capacity had taken admission resulting in a decline of nearly $20 \%$ as compared to the admitted students in the year 200910. As a consequence, a decline of $13.3 \%$ may be noted in the number of admitted students for the year 2018-19 in comparison with the increase of $15 \%$ in the intake.

The gender dimension of the enrollment statistics displays some interesting results which are evident from table 4. A total of 16,164 girls were admitted out of 58,881 admitted students which is $27.4 \%$. But in the year 2018-19, $24.34 \%$ i.e. 11,782 girls enrolled to the Polytechnic colleges out of a total 48,394 enrolled students [1]. From this data, it is to be clearly seen that there is an overall decline of 3 percentage points in girl's enrollment to the Polytechnic colleges during the last decade. The worrisome feature that is to be observed here is that, consecutively during the last five years, the enrollment of Girl students is declining which was maximum i.e. $-25 \%$ in the year 2015-16. Even last year also the same is $-10.2 \%$. Figure 1 shows this information. This declining trend is observed despite the reservations of seats for girl students along with other facilities provided by the government.

As per the data available from the Department of Technical Education, during the last five years there is considerable decrease in the overall number of admissions to the Polytechnic colleges between the academic years 2015-16 to 2019-20 which is shown in figure 2. The total number of students enrolled for diploma courses in the academic year 2015-16 was 61,000 but this number fell down to 41,732 for the academic year 2019-20. In terms of percentage, this decline in the admissions is to the extent of $31.5 \%$. The overall picture that emerges out of the above statistical analysis is that, at present the students are enrolling to little more than $50 \%$ of the intake capacity and nearly half of the total intake is falling vacant resulting in underutilization of infrastructure, teaching and non teaching manpower and laboratory facilities. 
Table 2: District Wise Distribution of Polytechnic Colleges in Karnataka (as on 31-03-2004 and 31-03-2019)

\begin{tabular}{|c|c|c|c|c|c|c|c|c|c|c|}
\hline \multicolumn{6}{|c|}{$31-03-2004$} & \multicolumn{5}{|c|}{ 31-03-2019 } \\
\hline $\begin{array}{c}\text { S. } \\
\text { No }\end{array}$ & District Name & نे & $\frac{\vec{d}}{2}$ & & है & ن & $\frac{\bar{d}}{2}$ & 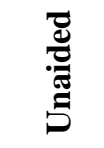 & 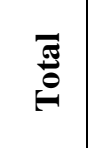 & 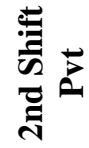 \\
\hline 1 & Bangalore (Urban) & 9 & 5 & 40 & 54 & 10 & 7 & 41 & 58 & 4 \\
\hline 2 & Bangalore (Rural) & 2 & 1 & 4 & 7 & 0 & 0 & 3 & 3 & 2 \\
\hline 3 & Bagalkote & Nil & 3 & Nil & 3 & 4 & 3 & 3 & 10 & 1 \\
\hline 4 & Belagavi & 1 & 3 & 6 & 10 & 2 & 3 & 10 & 15 & 4 \\
\hline 5 & Bellari & 1 & 1 & 5 & 7 & 3 & 2 & 7 & 12 & Nil \\
\hline 6 & Bidar & 1 & 1 & 2 & 4 & 2 & 1 & 4 & 7 & Nil \\
\hline 7 & Chamarajanagar & 1 & Nil & Nil & 1 & 1 & Nil & Nil & 1 & 1 \\
\hline 8 & Chikballapur & Nil & Nil & Nil & Nil & 2 & 1 & 1 & 4 & Nil \\
\hline 9 & Chikkamagalur & 1 & Nil & 2 & 3 & 1 & 1 & 1 & 3 & Nil \\
\hline 10 & Chitradurga & Nil & 1 & 2 & 3 & 3 & 1 & 4 & 8 & Nil \\
\hline 11 & Davangere & 1 & 2 & Nil & 3 & 3 & 2 & 2 & 7 & 2 \\
\hline 12 & Dharwad & 1 & 3 & 4 & 8 & 2 & 3 & 8 & 13 & Nil \\
\hline 13 & Dakshina Kannada & 2 & Nil & 3 & 5 & 4 & 3 & 5 & 12 & 1 \\
\hline 14 & Gadag & Nil & 2 & Nil & 2 & 2 & 2 & 3 & 7 & Nil \\
\hline 15 & Hassan & 2 & Nil & 1 & 3 & 4 & Nil & 4 & 8 & 2 \\
\hline 16 & Haveri & Nil & 1 & 1 & 2 & 2 & 1 & 2 & 5 & 1 \\
\hline 17 & Kalaburagi & 2 & 2 & 5 & 9 & 4 & 2 & 8 & 14 & Nil \\
\hline 18 & Kodagu & 1 & Nil & 1 & 2 & 1 & Nil & 1 & 2 & Nil \\
\hline 19 & Kolar & 3 & 1 & 5 & 9 & 3 & Nil & 6 & 9 & Nil \\
\hline 20 & Koppal & 2 & Nil & 1 & 3 & 3 & 1 & 2 & 6 & Nil \\
\hline 21 & Mandya & 1 & Nil & 2 & 3 & 3 & Nil & 3 & 6 & Nil \\
\hline 22 & Mysore & 1 & 4 & 5 & 10 & 2 & 4 & 6 & 12 & Nil \\
\hline 23 & Raichur & 1 & Nil & 1 & 2 & 3 & Nil & 2 & 5 & Nil \\
\hline 24 & Shivamogga & 3 & 1 & 3 & 7 & 4 & 3 & 3 & 10 & Nil \\
\hline 25 & Tumkuru & 1 & 1 & 5 & 7 & 2 & 1 & 9 & 12 & 3 \\
\hline 26 & Udupi & Nil & 1 & 3 & 4 & 2 & 1 & 3 & 6 & Nil \\
\hline 27 & Uttara Kannada & 1 & 1 & 3 & 5 & 4 & 2 & 2 & 8 & Nil \\
\hline 28 & Vijayapura & 1 & Nil & 2 & 3 & 2 & Nil & 4 & 6 & Nil \\
\hline 29 & Yadgir & Nil & Nil & Nil & Nil & 1 & 0 & 4 & 5 & 1 \\
\hline 30 & Ramnagara & Nil & Nil & Nil & Nil & 3 & 0 & 1 & 4 & 1 \\
\hline & TOTAL & 39 & 34 & 106 & 179 & 82 & 44 & 152 & 278 & 23 \\
\hline & ercentage $(\%)$ Increase & & & & & 52.4 & 23 & 30.26 & 35.6 & \\
\hline
\end{tabular}

Source: 1. All India Council for Technical Education. Website: www.aicte.ernet.in

2. Compiled from Annual Administrative Reports 2008-09 and 2018-19 
Table 3: Total Intake and Admissions in Polytechnic Colleges of Karnataka

\begin{tabular}{|c|c|c|c|c|c|c|c|}
\hline \multirow{2}{*}{ S.No } & \multirow{2}{*}{$\begin{array}{l}\text { Category of } \\
\text { Institution }\end{array}$} & \multicolumn{3}{|c|}{ 2009-10 } & \multicolumn{3}{|c|}{ 2018-19 } \\
\hline & & $\begin{array}{c}\text { No of } \\
\text { Colleges }\end{array}$ & Intake & Admission & $\begin{array}{c}\text { No of } \\
\text { Colleges }\end{array}$ & Intake & Admission \\
\hline 1 & Government & 81 & 20,881 & 17,598 & 82 & 21,592 & 16,686 \\
\hline 2 & Aided & 43 & 12,516 & 11,145 & 44 & 13,528 & 10,186 \\
\hline 3 & Unaided & 149 & 40,385 & 27,081 & 152 & 51,744 & 21,522 \\
\hline 4 & TOTAL & 273 & 73,782 & $\begin{array}{c}55,824 \\
(75.6 \%)\end{array}$ & 278 & 86,894 & $\begin{array}{l}48394 * \\
(55.7 \%)\end{array}$ \\
\hline \multicolumn{2}{|c|}{ Percentage change } & & & & $1.80 \%$ & $15 \%$ & $-13.3 \%$ \\
\hline
\end{tabular}

*Includes 2nd Shift 23 Colleges admission

Source: Compiled from Annual Administrative Reports 2008-09 and 2018-19

Table 4: Admission Statistics for Polytechnic Colleges of Karnataka during last 10 years

\begin{tabular}{|c|c|c|c|}
\hline Year & Boys & Girls & Total \\
\hline $2009-10$ & 42,717 & 16,164 & 58,881 \\
\hline $2010-11$ & $40490(-5.2 \%)$ & $15810(-2.2 \%)$ & $56300(-4.38 \%)$ \\
\hline $2011-12$ & $47417(+14.6 \%)$ & $20321(+22.2 \%)$ & $67738(+16.88 \%)$ \\
\hline $2012-13$ & $48100(+1.4 \%)$ & $21514(+5.5 \%)$ & $69614(+2.7 \%)$ \\
\hline $2013-14$ & $47904(-0.4 \%)$ & $23213(+7.3 \%)$ & $71117(+2.1 \%)$ \\
\hline $2014-15$ & $37101(-22.5 \%)$ & $24734(+6.1 \%)$ & $61835(-13 \%)$ \\
\hline $2015-16$ & $41282(+10 \%)$ & $18530(-25 \%)$ & $59812(-3.3 \%)$ \\
\hline $2016-17$ & $44621(+7.5 \%)$ & $13974(-24.6 \%)$ & $58595(-2 \%)$ \\
\hline $2017-18$ & $40835(-8.5 \%)$ & $13122(-6 \%)$ & $53957(-7.9 \%)$ \\
\hline $2018-19$ & $36612(-10.3 \%)$ & $11782(-10.2 \%)$ & $48,394 *(-10.3 \%)$ \\
\hline
\end{tabular}

*Includes 2nd Shift 10 Colleges Admission

Source: Compiled from Annual Administrative Reports 2008-09 and 2018-19

(Percentage in Parentheses displays year on year change)

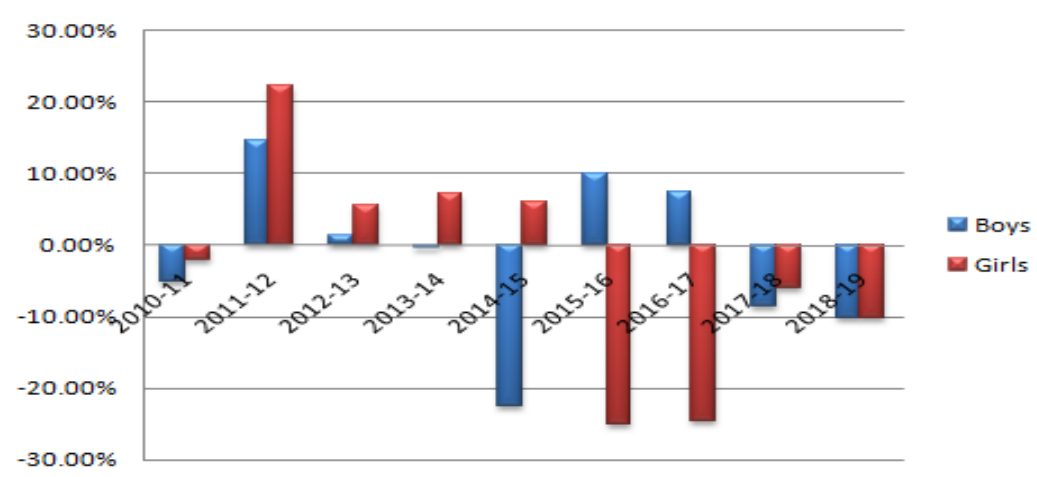

Figure 1: Gender dimension of admission to Polytechnic colleges of Karnataka 


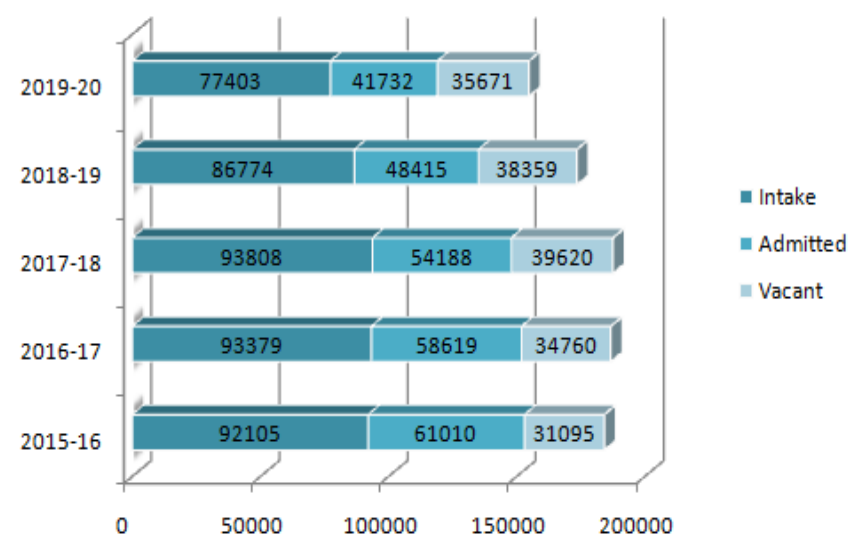

Source: Department of Technical Education, Bangalore

Figure 2: Year Wise Admission Data

\section{RESULTS AND DISCUSSION}

In this paper, the statistical information on the number of colleges, intake capacity and enrollment of students is collected mainly from the Annual Administrative Reports, Department of Technical Education, Bangalore. Following are some of the inferences which may be drawn from the above information.

- During the last 10 years, there is a marginal increase in the number of Polytechnic colleges in Karnataka from 283 to 300

- Accordingly the intake capacity of the students to Polytechnic colleges has also increased from 73,782 to 77,403 during the same period.

- But the alarming feature that is to be noted here is that, the enrollment of students to these colleges is declining which was $75.6 \%$ of the total intake in the year 2009-10, has fallen to $53.9 \%$ in the year 201920. As a result of this decline, at present nearly $50 \%$ of the seats in all the Polytechnic colleges in the state are remaining vacant.

- Particularly during the last five years, this decline of total enrollment of students to Polytechnic colleges in the state is very prominent $(31.5 \%)$.

- One more highlighting feature of this data is that, even the girl students' admission to the Polytechnic colleges is also showing a negative trend despite the government reservation of seats for girl students and also the existence of separate Women's Polytechnic colleges in the state.

Very recently, the diploma course was very desirable for the students after SSLC/ $10^{\text {th }}$ pass in the state. But nowadays, the interest of the students in these courses is slowly receding inspite of the fact that the government has introduced various student friendly schemes through the Department of Technical Education like free education to SC/ST students, children of HIV infected and Soldiers, free laptops for students, reservation of seats for girl students, number of scholarships', etc [5]. It appears that the students are not eager in taking up the diploma courses. The author has discussed this issue with many senior faculty members of the
Polytechnic colleges in the state. Several of these faculty members have been very open in giving their opinions in view of this declining trend of student enrollment. Similarly the author has discussed this issue with students of the Polytechnic colleges also. The students were also equally open in expressing their views. Taking into consideration the opinions of the faculty members and also the views of the students, the rationale for the declining trend of Polytechnic admissions may be enlisted below.

- During the last five years, there is massive increase in the number of PUC colleges in the state. The students are open to several options after completion of the PUC course. Hence the students are taking to the route of pre-university course to join the professional courses as the options are plenty. This has reduced the number of takers to Polytechnic courses. In this regard, the Government needs to rethink while granting permission to the PUC colleges.

- Majority of the students have expressed their opinion that the present online admission procedure which is adopted for enrollment to Polytechnic courses is rather complicated. Since these students are coming from the lower strata of society from rural areas, they are hardly exposed to the online facilities. But in case of admissions to pre-university courses, the admission process is very simple as compared to the Polytechnic admission process.

- The admission process to the pre-university course commences as soon as the declaration of the state's $\mathrm{SSLC} / 10^{\text {th }}$ results but the online interactive counseling timing for admission to Polytechnic courses is scheduled much later than the PUC admission process. As a consequence of this delay in fixing the time schedule for Polytechnic admission, nearly half of the students get admitted to the PUC colleges as there is lot of uncertainty in getting the course and also the college of their choice in case of Polytechnic education.

- There is lack of awareness among the parents and students hailing from rural areas, regarding the availability of the option of Polytechnic course after $\mathrm{SSLC} / 10^{\text {th }}$ pass and the future career opportunities.

- From the academic year 2019-20, the AICTE has brought down the intake of direct admission to second year engineering courses for diploma holders from $20 \%$ to $10 \%$ of the approved seats [10]. Hence the students are opting for the PUC courses which enable a much larger number of them, to pursue engineering courses.

- One more important fact that is to be noted recently is that, the mushrooming of Polytechnic colleges has led to the issue of vacant seats. Not all Polytechnic colleges witness the issue of vacant seats, but those lacking in terms of laid down benchmark facilities struggle to get admissions [8].

- The diploma holders, who pass out from the Polytechnic colleges, do not possess the technical skills which the industries demand in the present day constantly changing technical scenario. Hence the 
resultant shrinking job opportunities is also an important reason for the declining enrollment.

- Dwindling of job opportunities for diploma holders were also seen as a reason for the decline of preference for the Polytechnic courses. The common opinion is, "At a time, when the companies are able to hire degree holders at low salaries, why will they go for diploma holders?" [9].

- NITs and IITs do not provide any provision of lateral entries. This is also one of the important reasons for the bright students not opting for Polytechnic courses.

All these above factors are mostly responsible for the declining trend in the student enrollment to the Polytechnic courses.

\section{POLICY INTERVENTIONS}

The broad objective of the Polytechnic education is to prepare the students for a professionally productive life and to encourage development of motivation and technical skills for continuous independent learning. In achieving this broad objective, Polytechnic education should train the middle level technical personnel. In their respective domains, they should be able to act as a liaison between their colleagues at senior and junior levels. The diploma holders, who passed out from the Polytechnic colleges two to three decades ago, now occupy senior positions in the industrial sector and have contributed significantly to the industrialization efforts of the country. The investment in the Polytechnic education system is a necessity as this forms a crucial input for national industrial development. Hence the need of the hour is to consolidate and strengthen the ongoing programmes incorporating the latest developments in the technical field. Development on these lines may help to halt the trend of declining enrollment of students to the Polytechnic colleges. In this context, the policy interventions are suggested below.

- At present, the Polytechnic colleges are by and large imparting traditional and conventional diploma programmes based on old fashioned teaching methods. This does not meet the fast changing requirements of today's industry/organizations. The pass outs from these colleges lack technical skills and most of the teachers do not have exposure to industry. Hence the student's industry internship needs to be implemented rigorously and made mandatory in all the Polytechnic colleges of the state.

- The administrative setup for managing Polytechnic colleges is highly centralized and does not provide flexibility to the institutions to respond to the needs of the society and organize courses in relevant and modern technologies like Artificial Intelligence, 3D Printing, Nanotechnology, Robotics, etc.

- The online interactive counseling procedure needs to be simplified keeping in mind the situations/conditions of the students coming from economically weaker sections and also from the rural areas. Further there is a necessity for the policy makers to rethink regarding the fixing of the time schedule of the online counseling procedure for
Polytechnic admission on par with the PUC admission process.

- In view of declining student enrollment to Polytechnic colleges, the AICTE needs to rethink on its decision regarding the reduction (from $20 \%$ to $10 \%$ ) in the percentage of reservation for lateral entry of Polytechnic students directly to the second year of engineering courses. It is better, if the earlier percentage $(20 \%)$ of reservation is restored.

- At present, the lateral entry provision is not provided to the diploma holders to get the admission to the national level institutes like IITs and NITs. This lateral entry provision needs to be extended even to the IITs and NITs of the country. This will attract the bright students to enroll to the Polytechnic colleges after SSLC $/ 10^{\text {th }}$ pass.

- To enhance the technical skills of the engineers along with practical exposure, it is better if the completion of the diploma course soon after SSLC $/ 10^{\text {th }}$ is made mandatory for the students who wish to pursue their engineering degree programme. This provides the students solid technical foundation which is the need of present day industries. This Policy Intervention may expand the job opportunities not only for diploma holders but also for the engineering graduates. This may ensure proper balance between PUC and Polytechnic colleges in the state.

In this context, it is pertinent to note that, The New Education Policy, 2019 has proposed the new pedagogical structure and the curricular framework for school education which is guided by $5+3+3+4$ stage design [6]. The first stage which is the Foundational Stage is for children between the age of 3 to 8 years. The second stage is the Preparatory Stage for the children between 8 to 11 years. Third is the middle stage for the children between 11 to 14 years. Fourth and final is the secondary stage for the adolescents between 14 to 18 years. The adolescents of this age group are studying in the grades $9^{\text {th }}$ to $12^{\text {th }}$. Here NEP is silent regarding the Polytechnic education. The summary of NEP report states that these adolescents will have access to vocational courses along with more traditional academic courses, with students having choice to 'mix and match'. In this new framework, there is hardly any mention regarding the prospects of Polytechnic education in the country

\section{CONCLUSION}

Technical Education is a crucial input in a country's industrial and economic development. The purpose of Polytechnic education which is an important component of technical education, is to train middle level technical personnel. Polytechnic education system in Karnataka has come a long way during the last few decades providing the middle level technical manpower which has contributed significantly towards the development of manufacturing, construction and service sectors. Over the period of time there is an expansion in the number of Polytechnic colleges in the state to meet the enhanced demands of the industries whereas on the contrary, the number of students enrolling to 
these colleges is showing a declining trend. Hence there is a need for balancing of the supply and demand of technical middle level manpower. This imbalance necessitates a loud thinking on this issue at the higher levels of policy making. In this context some policy interventions are suggested in this paper which may go a long way not only to arrest but also to reverse this declining trend of students' enrollment to the Polytechnic colleges in Karnataka in the days to come.

\section{ACKNOWLEDGEMENT}

The author expresses his sincere gratitude to the faculty members and students for sparing their time and sharing their opinions.

\section{REFERENCES}

[1] Annual Administrative Reports 2008-09 and 2018-19, Department of Technical Education, Bangalore, Karnataka, India.

[2] Growth and Development of the Polytechnic Education in India with special Reference to Karnataka. Available online: https://shodhganga.inflibnet.ac.in/bitstream/10603/96675/9/09_chapt er\%203.pdf

[3] Present status of Polytechnic Education in India. Available Online: https://shodhganga.inflibnet.ac.in/bitstream/10603/7053/8/08_chapte r\%203.pdf

[4] Tapas Kumar Saha, Soumyendra Nath Basu, Partho Sarathi Bhattacharya,"Quality Perspective of Polytechnic Education in West Bengal", International Journal of Advanced Engineering, Management and Science, Volume 2, Issue 7, pp. 998-992, July 2016.

[5] Rashmi Belur (April 04, 2020), Deccan Herald, Daily newspaper. Available Online: https://www.deccanherald.com/state/topkarnataka-stories/diploma-courses-losing-sheen-have-few-takers821817.html

[6] National Education Policy 2019, Summary. Available Online: https://mhrd.gov.in/sites/upload_files/mhrd/files/nep/English1.pdf

[7] All India Council of Technical Education (AICTE). Online Available: https://facilities.aicteindia.org/dashboard/pages/angulardashboard.php\#!/approved

[8] http://timesofindia.indiatimes.com/articleshow/69298054.cms?utm source $=$ contentofinterest\&utm_medium $=$ text\&utm_campaign $=$ cppst

[9] https://www.hindustantimes.com/education/students-rejectengineering-diplomas-in-maharashtra-prefer-itis-instead-ofpolytechnics/story-eqtXr6857a9kslGDQMvssM.html

[10] http://www.aicte-india.org/news?date_value $\% 5$ Bvalue $\% 5$ D\&page $=4$ 